\title{
Estradiol Acutely Potentiates Hippocampal Excitatory Synaptic Transmission through a Presynaptic Mechanism
}

\author{
Tereza Smejkalova and Catherine S. Woolley \\ Department of Neurobiology and Physiology, Northwestern University, Evanston, Illinois 60208
}

\begin{abstract}
Although recent evidence suggests that the hippocampus is a source of $17 \beta$-estradiol (E2), the physiological role of this neurosteroid E2, as distinct from ovarian E2, is unknown. One likely function of neurosteroid E2 is to acutely potentiate excitatory synaptic transmission, but the mechanism of this effect is not well understood. Using whole-cell voltage-clamp recording of synaptically evoked EPSCs in adult rat hippocampal slices, we show that, in contrast to the conclusions of previous studies, E2 potentiates excitatory transmission through a presynaptic mechanism. We find that E2 acutely potentiates EPSCs by increasing the probability of glutamate release specifically at inputs with low initial release probability. This effect is mediated by estrogen receptor $\beta(\operatorname{ER} \beta)$ acting as a monomer, whereas $\operatorname{ER} \alpha$ is not required. We further show that the E2-induced increase in glutamate release is attributable primarily to increased individual vesicle release probability and is associated with higher average cleft glutamate concentration. These two findings together argue strongly that E2 promotes multivesicular release, which has not been shown before in the adult hippocampus. The rapid time course of acute EPSC potentiation and its concentration dependence suggest that locally synthesized neurosteroid E2 may activate this effect in vivo.
\end{abstract}

\section{Introduction}

Recent studies support the idea that the hippocampus, a known target of the steroid hormone $17 \beta$-estradiol (E2), is also a site of E2 synthesis. The possibility that the brain produces its own steroids, neurosteroids, was first proposed almost 30 years ago (Corpechot et al., 1981). More recently, all enzymes needed to synthesize E2 from cholesterol, as well as significant levels of intermediate metabolites and E2 itself, have been demonstrated in the adult rat hippocampus (Kimoto et al., 2001; Hojo et al., 2004, 2009). This raises the question, what is the physiological role of neurosteroid E2 as distinct from ovarian E2?

One likely answer lies in the ability of E2 to acutely potentiate excitatory synaptic transmission. Within minutes of application to hippocampal slices, E2 increases field EPSP slope (Teyler et al., 1980; Sharrow et al., 2002; Kim et al., 2006; Kramar et al., 2009) and potentiates intracellularly recorded EPSPs and EPSCs in CA1 (Wong and Moss, 1992; Foy et al., 1999; Rudick and Woolley, 2003). E2 also acutely increases CA1 neurons' responses to glutamate receptor agonists applied to slices (Wong and Moss, 1992) or dissociated cells ( $\mathrm{Gu}$ and Moss, 1996, 1998). Several observations suggest that brain-derived E2, not ovarian E2, is the endogenous steroid that activates these effects in vivo. First, although acute potentiation can occur with E2 concentrations matching peak circulating levels $(\sim 100 \mathrm{pM})$, it is more robust with higher concentrations, and potentiation of agonist-evoked responses requires $\geq 10 \mathrm{~nm}$ E2. Second, acute potentiation occurs in slices

Received Aug. 9, 2010; revised Sept. 21, 2010; accepted Sept. 23, 2010.

This work was supported by National Institutes of Health Grants NS037324, MH067564, and RR015497. We thank Indira Raman for helpful discussions.

Correspondence should be addressed to Dr. Catherine S. Woolley, Department of Neurobiology and Physiology, 2205 Tech Drive, Northwestern University, Evanston, IL 60208. E-mail: cwoolley@northwestern.edu.

DOI:10.1523/JNEUROSCI.4161-10.2010

Copyright $\odot 2010$ the authors $\quad 0270-6474 / 10 / 3016137-12 \$ 15.00 / 0$ from male as well as female hippocampus (Teyler et al., 1980; Kramar et al., 2009). Finally, the ability of $\mathrm{E} 2$ to act within minutes is much more rapid than any fluctuations in circulating E2.

The mechanism(s) of acute potentiation of synaptic transmission by $\mathrm{E} 2$ are not well understood. Intracellular recording studies have shown that only some CA1 cells are E2 responsive, suggesting that $\mathrm{E} 2$ action is cell specific. Furthermore, the studies using exogenous agonist application led to the conclusion that E2 enhances postsynaptic sensitivity to glutamate. It is not clear, however, whether conclusions based on nonsynaptic stimulation apply to E2 effects on synaptic transmission. Therefore, we studied acute potentiation of synaptic responses by E2 using wholecell voltage-clamp recording of synaptically evoked EPSCs in adult rat hippocampal slices. Consistent with previous reports, we observed a response to E2 in only a subset of experiments. Interestingly, however, the E2-responsive subset shared the characteristic of relatively high initial paired-pulse ratio (PPR), and E2 decreased PPR in parallel with synaptic potentiation, suggestive of presynaptic mechanisms. Indeed, we found that $\mathrm{E} 2$ acutely potentiates excitatory synaptic transmission in an input-specific manner, through an increase in the probability of glutamate release specifically at inputs with low initial release probability. This potentiation depends on activation of estrogen receptor $\beta(E R \beta)$ and not ER $\alpha$. Further investigation of mechanisms involved in the E2-induced increase in glutamate release revealed that E2 increases individual vesicle release probability as well as average cleft glutamate concentration, strongly suggesting that E2 promotes multivesicular release.

\section{Materials and Methods}

Animals. All animal procedures were performed in accordance with the National Institutes of Health Guide for the Care and Use of Laboratory Animals and were approved by the Northwestern University Animal Care and Use Committee. Adult female Sprague Dawley rats (50-60 d old; 
Harlan) were ovariectomized under ketamine ( $85 \mathrm{mg} / \mathrm{kg}$, i.p; Bioniche Pharma) and xylazine (13 mg/kg, i.p.; Lloyd Laboratories) anesthesia using aseptic surgical procedures. Either 3 or $7 \mathrm{~d}$ after surgery, each rat was given two injections (subcutaneously) of $10 \mu \mathrm{g}$ of $17 \beta$-estradiol benzoate in $100 \mu \mathrm{l}$ of sesame oil, $24 \mathrm{~h}$ apart, and slices were prepared $2 \mathrm{~d}$ after the second injection. This estradiol pretreatment produces serum levels of $\sim 30-40 \mathrm{pg} / \mathrm{ml}$ (corresponding to peak proestrus levels) (Smith et al., 1975) at the time the animal is killed (Woolley and McEwen, 1993), and has been shown to increase CA1 responsiveness to acute effects of estradiol on excitatory synaptic transmission (Wong and Moss, 1992).

Chemicals. Stock solutions of the following drugs were prepared in DMSO: (+)-bicuculline, cyclothiazide (CTZ), propylpyrazole triol (PPT), diarylpropionitrile (DPN), ICI 182,870, 2,3-dioxo-6-nitro1,2,3,4-tetrahydrobenzo[f]quinoxaline-7-sulfonamide (NBQX), G-1 (all from Tocris Bioscience), and $17 \beta$ - and $17 \alpha$-estradiol (SigmaAldrich). Stock solutions of $\gamma$-D-glutamylglycine ( $\gamma \mathrm{DGG})$ and $(R S)-3$ (2-carboxypiperazin-4-yl)-propyl-1-phosphonic acid [(RS)-CPP] (both from Tocris Bioscience) were prepared in $\mathrm{ddH}_{2} \mathrm{O}$. Stock solutions were diluted in artificial CSF (ACSF) on the day of recording to the final concentrations indicated. Control ACSF contained an equivalent concentration of DMSO $(<0.1 \%)$. Other chemicals were either from Fisher Scientific $\left(\mathrm{NaCl}, \mathrm{NaHCO}_{3}\right.$, dextrose, $\mathrm{KCl}$, and $\left.\mathrm{NaH}_{2} \mathrm{PO}_{4}\right)$ or from Sigma-Aldrich (sesame oil, $\mathrm{CaCl}_{2}, \mathrm{MgCl}_{2}, \mathrm{~K}$-gluconate, HEPES, $\mathrm{Na}_{2}$ creatine phosphate, MgATP, NaGTP, biocytin, and QX314).

Slice preparation and electrophysiology. Rats were deeply anesthetized with sodium pentobarbital $(80 \mathrm{mg} / \mathrm{kg}$, i.p.; Virbac Animal Health) and perfused transcardially with ice-cold oxygenated ACSF containing the following (in $\mathrm{mm}$ ): $125 \mathrm{NaCl}, 25 \mathrm{NaHCO}_{3}, 25$ dextrose, $2.5 \mathrm{KCl}, 1.25$ $\mathrm{NaH}_{2} \mathrm{PO}_{4}, 1 \mathrm{MgCl}_{2}$, and $2 \mathrm{CaCl}_{2}, 315$ Osm, $\mathrm{pH}$ 7.4. Transverse slices of dorsal hippocampus $(300 \mu \mathrm{m})$ were cut into an ice-cold bath of oxygenated ACSF using a Leica VT1000S oscillating tissue slicer. Slices were allowed to recover submerged in oxygenated ACSF at $35^{\circ} \mathrm{C}$ for $30 \mathrm{~min}$ and were then kept at room temperature until recording. During recording, slices were perfused with warm $\left(32-35^{\circ} \mathrm{C}\right)$ or room temperature $\left(20-22^{\circ} \mathrm{C}\right.$, for high-frequency train experiments and $\gamma \mathrm{DGG} / \mathrm{NBQX}$ experiments) oxygenated ACSF at a rate of $\sim 2 \mathrm{ml} / \mathrm{min}$ in a recording chamber mounted on a Zeiss Axioskop. Somatic whole-cell voltageclamp recordings were obtained from visually identified CA1 pyramidal cells using patch electrodes (3-5 M 2 ) filled with intracellular solution containing the following (in mM): $115 \mathrm{~K}$-gluconate, $20 \mathrm{KCl}, 10 \mathrm{HEPES}$, $10 \mathrm{Na}_{2}$-creatine phosphate, $2 \mathrm{MgATP}, 0.3 \mathrm{NaGTP}, 0.1 \%$ biocytin, and 1-5 QX314, 280 Osm, pH 7.3. One or two glass bipolar stimulating electrodes filled with ACSF were placed in the stratum radiatum $\sim 300$ $\mu \mathrm{m}$ apart. At the beginning of every double-stimulation experiment, it was confirmed that no paired-pulse facilitation [interpulse interval (IPI), $100 \mathrm{~ms}$ ] occurred when the first pulse was delivered at one stimulation site and the second pulse was delivered at the other stimulation site, indicating no overlap of stimulated inputs. During an experiment, paired-pulse stimulation (IPI, 100 or $50 \mathrm{~ms}$ ) was delivered every $15 \mathrm{~s}$; in double-stimulation experiments, stimulation was delivered every $15 \mathrm{~s}$, alternating between the two stimulation sites; in high-frequency train experiments, $2 \mathrm{~min}$ of paired-pulse stimulation (delivered every $15 \mathrm{~s}$ ) alternated with $3 \mathrm{~min}$ of train stimulation (100-pulse, $20 \mathrm{~Hz}$ trains delivered every $45 \mathrm{~s}$ ). In experiments using both 50 and $100 \mathrm{~ms}$ IPI, there were no effects of IPI on either baseline PPR or the E2 effect on PPR. Series resistance was monitored using $5 \mathrm{mV}, 10 \mathrm{~ms}$ voltage steps and ranged between 5 and $25 \mathrm{M} \Omega$ between experiments. Only experiments with stable series resistance and holding current were included in the analysis, and series resistance did not differ between E2-responsive and E2nonresponsive experiments. Synaptically evoked AMPA-receptormediated EPSCs were recorded at a holding potential of $-70 \mathrm{mV}$ in the presence of the $\mathrm{GABA}_{\mathrm{A}}$ and NMDA receptor blockers, (+)-bicuculline $(10 \mu \mathrm{M})$ and $(R S)-\mathrm{CPP}(10 \mu \mathrm{M})$, respectively. Data were acquired with an Axopatch 200B amplifier and pClamp 9.0 software (Molecular Devices), filtered at $2 \mathrm{kHz}$, and digitized at $20 \mathrm{kHz}$ using a Digidata $1322 \mathrm{~A}$ data acquisition system (Molecular Devices).

After a stable 10-15 min baseline recording in control ACSF, different drugs were bath applied as follows: E2 (100 pM to $100 \mathrm{~nm}$ ) for $10-15 \mathrm{~min}$, in most cases followed by a 10-30 min washout period; CTZ (100 $\mu \mathrm{M})$,
PPT (100 or $200 \mathrm{~nm}$ ), DPN (100 or $500 \mathrm{~nm}$ ), ICI 182,780 (100 nm), or G-1 (100 nM) alone for $12 \mathrm{~min}$, followed by coapplication with E2 (100 nм) for $12 \mathrm{~min}$, followed by E2 (100 nM) alone (see Fig. 4); $\gamma \mathrm{DGG}$ (1 mM) for $10 \mathrm{~min}$ either in the absence or presence of E2 (100 nM) (see Fig. 6); $\operatorname{NBQX}(200 \mathrm{~nm})$ for $15 \mathrm{~min}$ either in the absence or in the presence of E2 (100 nm) (see Fig. 6). Effects of different drugs were evaluated by comparing data from the last $5 \mathrm{~min}$ of recording in each condition or from a 5 min period after the maximal effect of a drug was reached (in $\gamma$ DGG and NBQX experiments). Because effects of E2 were not readily reversible, E2 and ER agonists were applied to each slice only once.

In experiments using high-frequency stimulus trains, a 15-20 min baseline recording was followed by a $20 \mathrm{~min}$ recording in the presence of E2 (100 nM). Effects of E2 were evaluated by comparing data from the last $10 \mathrm{~min}$ of $\mathrm{E} 2$ application to data from the last $10 \mathrm{~min}$ of baseline to include a sufficient number of train sweeps. The analysis of trains was based on Schneggenburger et al. (1999) and Wesseling and Lo (2002). Baseline EPSC trains showed early facilitation followed by gradual depression, and reached a steady state after $\sim 70$ pulses, consistent with previous reports (Wesseling and Lo, 2002). The cumulative EPSC charge during the last second of the train (sum of pulses 81-100) was used to estimate the rate of steady-state release attributable to vesicle replenishment, assumed to be constant throughout the train. The relative size of the readily-releasable vesicle pool (RRP) was estimated from the cumulative EPSC charge recorded before the steady state was reached (sum of pulses 1-80) after subtracting the EPSC charge caused by vesicle replenishment during the train (four times the sum of pulses 81-100). The proportion of the total RRP released by the first stimulus was used to estimate the relative individual vesicle release probability, $P_{\text {ves }}$.

Data were analyzed off-line using Igor Pro (Wavemetrics) software, and statistical significance was evaluated with Student's $t$ tests or ANOVA followed by Bonferroni post hoc tests, as indicated. A $p$ value of $<0.05$ was considered significant.

\section{Results}

\section{$17 \beta$-Estradiol acutely potentiates EPSC amplitude in a subset of experiments}

We investigated the ability of E2 to rapidly potentiate excitatory synaptic transmission in adult female rat hippocampus. We stimulated the Schaffer collateral pathway in acute slices and made whole-cell voltage-clamp recordings of synaptically evoked EPSCs from CA1 pyramidal cells. In a subset of experiments, bath application of E2 (100 pM to $100 \mathrm{~nm}$ ) potentiated EPSC amplitude within minutes (Fig. $1 A$ ). This effect was not readily reversible, possibly because of slow wash out of E2 from the slice or initiation of a persistent effect that outlasts the presence of E2. We quantified EPSC potentiation by normalizing average EPSC amplitude recorded during the last $5 \mathrm{~min}$ in E2 to baseline EPSCs during the last $5 \mathrm{~min}$ before $\mathrm{E} 2$ application. This showed that the magnitude of E2-induced potentiation ranged from 0.76 to 1.76 , with a clearly bimodal distribution among experiments (Fig. $1 \mathrm{~B}$ ). Based on this distribution, we subsequently divided all experiments into two groups: those showing $>20 \%$ potentiation were classified as E2 responsive and the rest as E2 nonresponsive.

Using the $>20 \%$ potentiation criterion, we found that both the frequency of responders and the extent of potentiation in responders increased with increasing concentrations of E2. At 100 pM, E2 potentiated EPSCs in 6 of 14 (43\%) experiments, by $26 \pm 2 \%$; $1 \mathrm{nM} \mathrm{E2}$ potentiated EPSCs in 9 of 22 (41\%) experiments, by $29 \pm 3 \%$; $10 \mathrm{nM}$ E2 potentiated EPSCs in 8 of $17(47 \%)$ experiments, by $33 \pm 4 \%$; and $100 \mathrm{~nm}$ E2 potentiated EPSCs in 18 of $28(64 \%)$ experiments, by $42 \pm 3 \%$ (Fig. 1C). The effect of E2 was stereospecific, as no potentiation was observed with $100 \mathrm{nM}$ $17 \alpha$-estradiol $(n=5)$. 

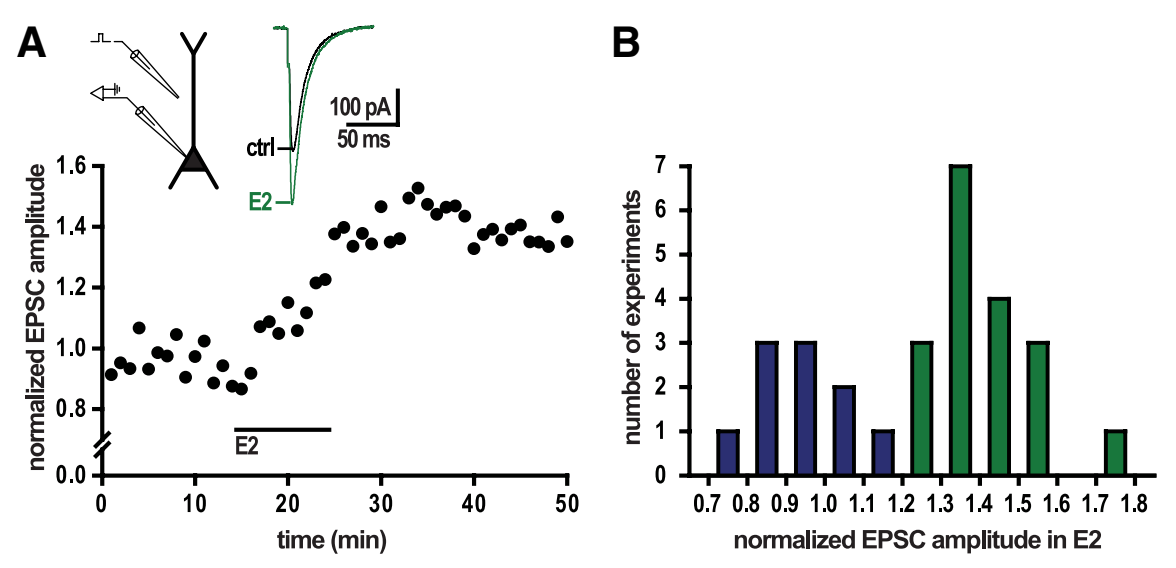

C

Figure 1. Estradiol acutely potentiates EPSC amplitude in a subset of experiments. EPSCs evoked by Schaffer collateral pathway stimulation were recorded from CA1 pyramidal cells in acute slices from adult female rats (see Materials and Methods). E2 (100 pм to $100 \mathrm{~nm}$ ) was bath applied for 10-15 min. A, Representative E2-responsive experiment illustrating the rapid time course of EPSC amplitude potentiation by E2. Inset, A schematic of electrode placement and individual current traces recorded during baseline and in E2. B, Bimodal distribution of EPSC potentiation by E2 (100 nM) used to classify experiments as E2 responsive ( $>20 \%$ increase; green) or E2 nonresponsive ( $\leq 20 \%$ increase; blue). C, Normalized EPSC amplitude in responders (green) and nonresponders (blue) with various concentrations of $17 \beta$-E2 (100 pm to $100 \mathrm{~nm})$ and $17 \alpha$-E2 (100 nM). Each open symbol represents an individual experiment; filled symbols represent mean \pm SEM for each condition. $p<0.01$; one-way ANOVA for normalized EPSC amplitude in E2-responsive experiments.

\section{E2 acutely influences presynaptic physiology}

Previous studies indicated that E2 acutely increases postsynaptic responsiveness to AMPA receptor agonists. The range in magnitude of EPSC potentiation we observed, however, raised the possibility that variation in $\mathrm{E} 2$ responsiveness might be related to differences in glutamate release properties, which are known to vary widely among CA1 synapses (Turner et al., 1997; Dobrunz and Stevens, 1997). Thus, we investigated potential presynaptic effect(s) of E2 by analyzing the PPR, a measure related to neurotransmitter release probability and commonly used to assess changes in presynaptic function.

We recorded EPSCs evoked by paired-pulse stimulation (IPI, $100 \mathrm{~ms}$ ) of the Schaffer collateral pathway and examined the effect of E2 on PPR in E2 responders and nonresponders. This revealed, first, that responders and nonresponders differed in baseline PPR even before E2 was applied (Fig. 2A,B). Baseline PPR in responders was $1.48 \pm 0.03$, significantly higher than the $1.37 \pm 0.02$ baseline PPR in nonresponders ( $t$ test, $p<0.01$ ). In addition, E2 decreased PPR within minutes of application specifically in responders (Fig. 2A) (one-way ANOVA, $p<0.01$ ), whereas it had no effect on PPR in nonresponders (Fig. $2 B$ ) (oneway ANOVA, $p>0.7)$. Since PPR is inversely related to release probability, these results suggest that E2 acts preferentially on synapses with relatively low initial probability of release to potentiate EPSC amplitude, at least in part, by increasing glutamate release probability.

Although AMPA receptor desensitization does not seem to influence EPSC amplitude or PPR during basal synaptic transmission (Hjelmstad et al., 1999), it could be upregulated during a potentiated state. If so, glutamate released by the first pulse in a paired-pulse experiment may desensitize some postsynaptic receptors, limiting the postsynaptic current recorded on the second pulse and decreasing PPR. To address this possibility, we examined the effects of E2 (100 nM) on EPSC amplitude and PPR in the presence of CTZ (100 $\mu \mathrm{M})$, which blocks AMPA receptor desensitization (Trussell et al., 1993). In 9 of 14 experiments with CTZ, E2 rapidly increased EPSC amplitude by $>20 \%$ (on average, by $33 \pm 4 \%$ ) (Fig. 2C). In these E2-responsive experiments, PPR was initially high and decreased in E2, from $1.53 \pm 0.08$ to $1.35 \pm 0.05$
(Fig. 2C) (one-way ANOVA for amplitude, $p<0.01$; one-way ANOVA for PPR, $p<0.01$ ), similar to results without CTZ. In the remaining 5 of 14 experiments in CTZ that were E2 nonresponsive, PPR was low and remained constant in E2 (Fig. 2D). Thus, the E2-induced decrease in PPR is not dependent on AMPA receptor desensitization.

PPR also can be influenced by differences in the quality of voltage clamp between experiments or over the course of an experiment. To investigate possible voltage-clamp artifact, we analyzed EPSC rise times in a subset of E2 experiments and found them to be comparable in responders and nonresponders and unchanged by E2 application (supplemental Fig. S1 A, available at www.jneurosci.org as supplemental material). Additionally, analyzing the coefficient of variation (CV) of EPSC amplitude (equal to SD/mean), a measure related to presynaptic parameters (a high CV reflects a low release probability and vice versa) (Malinow and Tsien, 1990), showed that baseline $\mathrm{CV}$ was higher in responders than nonresponders and that E2 acutely decreased CV specifically in responders (supplemental Fig. S1 B) (two-way ANOVA, interaction, $p<0.01$ ). Thus, the most plausible interpretation of our results is that $\mathrm{E} 2$ rapidly increases glutamate release probability preferentially at those synapses where baseline release probability is relatively low. To our knowledge, this is the first demonstration that E2 acutely regulates presynaptic physiology in the hippocampus.

\section{E2-induced EPSC potentiation and PPR decrease are input specific}

The observation that $\mathrm{E} 2$ responsiveness is related to baseline PPR, a presynaptic characteristic, is difficult to reconcile with the postsynaptic mechanism of E2 action deduced from previous studies. Moreover, the rapid decrease in PPR observed during E2 application points to a presynaptic effect. These results suggest that $\mathrm{E} 2$ responsiveness could be a property of specific inputs to a postsynaptic cell, rather than of the postsynaptic cell itself.

To examine this possibility, we delivered paired-pulse stimulation to two nonoverlapping sites in the stratum radiatum and recorded EPSCs from a common postsynaptic CA1 pyramidal 
cell. Interestingly, bath application of E2 often affected the two sets of inputs on a single postsynaptic cell differently. In the most extreme cases ( $n=9$ of 31) (Fig. $3 A-C$ ), EPSCs were potentiated by $>20 \%$ at one set of inputs (average normalized EPSC amplitude in E2, $1.30 \pm 0.02$ ), whereas no EPSC potentiation occurred at the other set of inputs to the same cell (average normalized EPSC amplitude in E2, $1.00 \pm 0.04)$. Furthermore, even when recorded from a common postsynaptic cell, E2-responsive inputs were characterized by a higher baseline PPR that decreased during E2 application, whereas E2-nonresponsive inputs had a lower baseline PPR that remained unaffected by E2 (Fig. $3 B, C$ ) (two-way ANOVA, effect of group, $p<0.05$; effect of $\mathrm{E} 2, p<0.05$; interaction, $p<0.05)$. There was no consistent relationship between E2 responsiveness and distance of the stimulating electrode from the cell body layer: in three of nine experiments, the E2-responsive inputs were more distal than the E2nonresponsive inputs, and in the other six of nine experiments, E2-responsive inputs were more proximal. In addition, there was no difference in EPSC rise times between E2-responsive and E2nonresponsive inputs from a common postsynaptic cell (data not shown) (paired $t$ test, $p>0.1$ ), arguing that the observed input-specific differences in response to E2 were not caused by voltage clamp error. Thus, the double-input experiments show that acute E2-induced EPSC potentiation (and the corresponding decrease in PPR) are input specific, rather than postsynaptic cell specific.

The observation that E2-induced EPSC potentiation depends on presynaptic inputs influences interpretation of the bimodal distribution of $\mathrm{E} 2$ responsiveness (Fig. 1B). EPSCs in our experiments reflect the composite response of multiple individual synapses, and thus should contain both E2-responsive and E2nonresponsive individual synapses in some proportion. This suggests that EPSCs resulting from activation of many inputs are likely to contain a mixture of E2-responsive and E2-nonresponsive individual synapses, and thus show EPSC potentiation of relatively small magnitude occurring in most experiments. In contrast, EPSCs resulting from activation of fewer inputs would be more likely to contain mostly E2-responsive or mostly E2-nonresponsive synapses, particularly if the distribution of $\mathrm{E} 2$-responsive versus $\mathrm{E} 2$-nonresponsive synapses is somewhat patchy, and to show EPSC potentiation of a larger magnitude but less frequently.

To test these predictions, we compared the effects of $\mathrm{E} 2$ in a subset of experiments with relatively small $(74 \pm 4 \mathrm{pA} ; n=25)$ versus large (185 $\pm 25 \mathrm{pA} ; n=31)$ EPSCs (supplemental Fig.

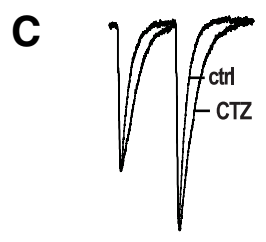

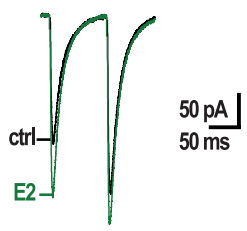
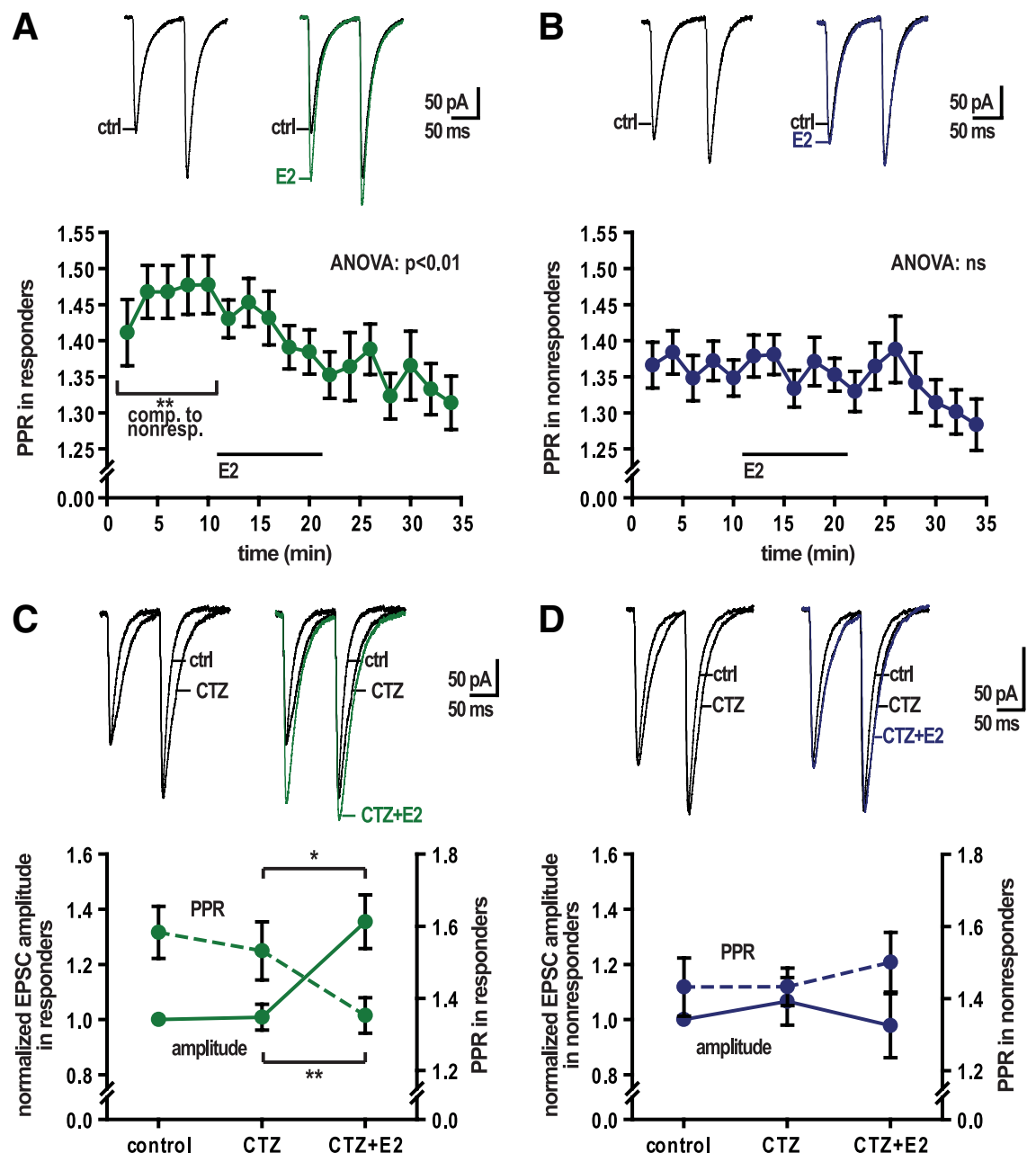

Figure 2. Estradiol acutely increases release probability. $\boldsymbol{A}, \boldsymbol{B}, \mathrm{EPSCS}$ were evoked by paired-pulse stimulation (interpulse interval, $100 \mathrm{~ms}$ ) before and during bath application of E2 (100 pм to $100 \mathrm{~nm}$ ). Experiments were classified as E2 responsive (green) or E2 nonresponsive (blue) based on $>20 \%$ EPSC amplitude potentiation. $\boldsymbol{A}$, Plot of mean \pm SEM PPR over time in E2-responsive experiments $(n=41)$. In E2-responsive experiments, PPR was high during baseline and decreased during E2 application (one-way ANOVA, $p<0.01$ ). ${ }^{* *} p<0.01$ (a significant difference between baseline PPR in E2-responsive versus E2-nonresponsive experiments; $t$ test). Top, Representative individual traces recorded during baseline and in E2. B, Plot of mean \pm SEM PPR over time in E2-nonresponsive experiments $(n=39)$. In E2-nonresponsive experiments, the PPR was relatively low during baseline and remained unchanged during $\mathrm{E} 2$ application (one-way ANOVA, $p>0.7$ ). Top, Representative individual traces recorded during baseline and in E2. C, D, Effects of E2 were examined while AMPAR desensitization was blocked with CTZ. EPSCs were recorded before and during bath application of CTZ $(100 \mu \mathrm{M})$, followed by bath application of CTZ (100 $\mu \mathrm{M})+$ E2 (100 nM). C, Plot of desensitization was blocked with CTZ (one-way ANOVA for EPSC amplitude, $p<0.01$; one-way ANOVA for PPR, $p<0.01$ ). ${ }^{*} p<$ amplitude between (TZ and CTZ + E2; Bonferroni post hoc test). Top, Representative individual traces recorded in indicated conditions. D, Plot of mean \pm SEM normalized EPSC amplitude (solid line) and PPR (dashed line) during baseline, in CTZ, and in CTZ + E2 in E2-nonresponsive experiments $(n=5)$. Top, Representative individual traces recorded in indicated conditions. See also supplemental Figure S1 (available at www.jneurosci.org as supplemental material).

S2A, available at www.jneurosci.org as supplemental material) selected to have the same baseline PPR (each $1.45 \pm 0.03$ ) (supplemental Fig. S2B). Thus, small and large EPSCs had similar proportions of low and high release probability synapses, on average, but small EPSCs likely contained fewer total synapses than large EPSCs. Consistent with our prediction, we found that large EPSCs tended to respond to E2 more frequently than small EPSCs (71 vs $64 \%$ ), but the magnitude of their response was significantly smaller than for small EPSCs ( $35 \pm 3 \%$ vs $47 \pm 5 \%$; $t$ test, $p<0.05$ ) (supplemental Fig. S2C). PPR decreased in E2 similarly for small and large EPSCs (two-way ANOVA, effect of E2, $p<0.01$; effect 
A
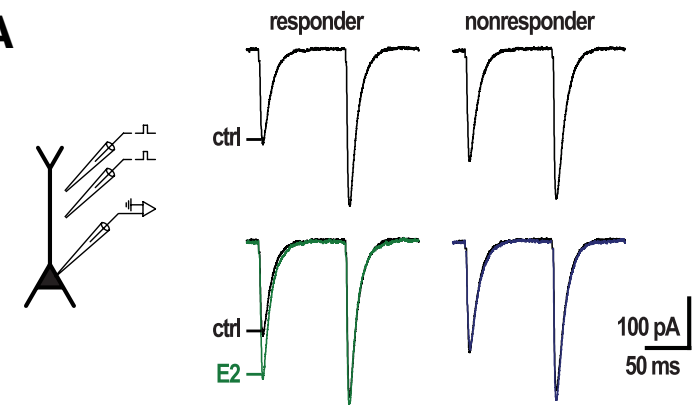

B
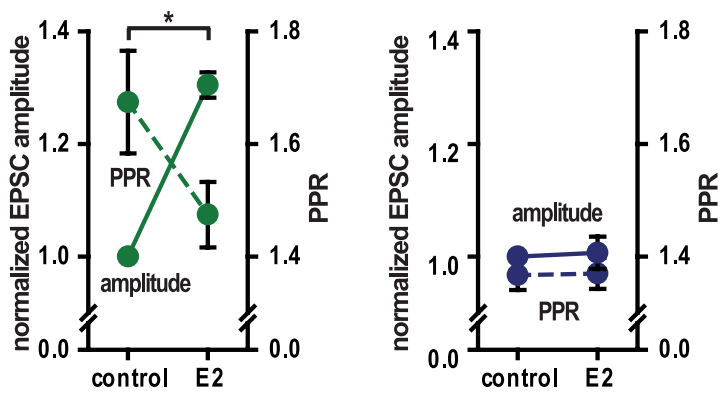

Figure 3. Estradiol-induced EPSC potentiation and PPR decrease are input specific. EPSCs were evoked by alternating paired-pulse stimulation of two nonoverlapping sets of Schaffer collateral inputs to a common CA1 pyramidal cell. $\boldsymbol{A}$, A schematic of electrode placement and representative individual current traces evoked at E2-responsive and E2nonresponsive inputs recorded from a single cell. $B$, Plot of mean \pm SEM normalized EPSC amplitude (solid line) and PPR (dashed line) at E2-responsive inputs (green; $n=9$ ); E2 decreased PPR in parallel with potentiating EPSCs in an input-specific manner. ${ }^{*} p<0.05$ (significant effect of E2 on PPR; paired $t$ test). C, Plot of mean \pm SEM normalized EPSC amplitude (solid line) and PPR (dashed line) at E2-nonresponsive inputs (blue) from the same cells as in $\boldsymbol{B}$. See also supplemental Figure $\mathbf{S 2}$ (available at www.jneurosci.org as supplemental material).

of initial EPSC size, $p>0.2$; interaction, $p>0.3$ ) (supplemental Fig. S2 $D$, available at www.jneurosci.org as supplemental material). Thus, our results are consistent with the idea that the E2 response of a composite EPSC reflects heterogeneous E2 responsiveness among the individual synapses it contains. Indeed, E2-induced potentiation of some individual synapses may be much more robust than the observed potentiation of composite EPSCs. This analysis also demonstrates that E2 responsiveness does not depend on baseline release probability alone, since small and large EPSCs with the same baseline PPR responded differently to E2. One likely possibility is that a synapse responds to E2 only if its initial release probability is sufficiently low and it possesses some additional factor, such as the appropriate estrogen receptor.

\section{E2 acutely potentiates EPSCs through ER $\beta$ activation}

Which ERs mediate acute EPSC potentiation? The hippocampus contains both classical ERs, $\mathrm{ER} \alpha$ and $\mathrm{ER} \beta$, and a portion of $\mathrm{ER} \alpha$ and $\mathrm{ER} \beta$ in CA1 is found at excitatory synapses both presynaptically and postsynaptically (Milner et al., 2001, 2005). We used the $\mathrm{ER} \alpha$ and $\mathrm{ER} \beta$ selective agonists, PPT (Stauffer et al., 2000) and DPN (Meyers et al., 2001), respectively, to investigate the roles of $\mathrm{ER} \alpha$ and $\mathrm{ER} \beta$ in acute EPSC potentiation. Based on the binding affinities of PPT and DPN for their preferred ERs, we used PPT at concentrations 100 or $200 \mathrm{~nm}$ and DPN at concentrations 100 or $500 \mathrm{~nm}$ to approximate the dose of E2 that was most effective (100 nM).
DPN both mimicked and occluded the effect of E2 to potentiate EPSCs, whereas PPT had no effect (Fig. 4A,B). In 12 of 23 experiments, DPN rapidly potentiated EPSC amplitude by $>20 \%$ (on average, by $30 \pm 2 \%$ ) (Fig. $4 C$ ). Additionally, in 15 of these experiments (8 DPN responsive, $7 \mathrm{DPN}$ nonresponsive), DPN application was followed by E2 (100 nM), which induced no further potentiation (Fig. 4A,C). Importantly, DPN also decreased PPR in parallel with potentiating EPSC amplitude, specifically in responsive inputs (Fig. $4 F, G$ ) (paired $t$ test, $p<0.01$ for responders; $p>0.2$ for nonresponders). In 5 of $11 \mathrm{DPN}$ experiments done with two stimulating electrodes to activate nonoverlapping inputs to a single cell, one input was potentiated by $>20 \%$, whereas the other was not responsive, and PPR decreased specifically at the potentiated input (data not shown) (paired $t$ test, $p<0.05$ for responsive inputs; $p>0.2$ for nonresponsive inputs). Thus, like with E2, DPN-induced EPSC potentiation is input specific, not postsynaptic cell specific.

In contrast to results with DPN, PPT failed to potentiate EPSC amplitude in any of 15 experiments. In 8 experiments, PPT application was followed by E2 (100 nM), and in 5 cases, E2 after PPT induced robust EPSC amplitude potentiation (Fig. $4 B, D$ ), showing that inputs that failed to respond to PPT were capable of responding to E2. Paired-pulse ratio also was unchanged by PPT (Fig. $4 H$ ) (paired $t$ test, $p>0.1$ ). Together, these results indicate that acute actions of E2 to potentiate EPSCs and decrease PPR are mediated by $\mathrm{ER} \beta$ and not by $\mathrm{ER} \alpha$. That DPN mimics both E2 effects is consistent with the idea that EPSC potentiation and decreased PPR are related, such that E2 acutely potentiates EPSCs by increasing glutamate release probability.

To further investigate the role of ERs in mediating acute EPSC potentiation, we used ICI 182,780, which binds $\operatorname{ER} \alpha$ and $\operatorname{ER} \beta$ with similar high affinity and behaves as an antagonist of classical nuclear ER activity in transcriptional assays (Sun et al., 2002) by blocking receptor dimerization (Fawell et al., 1990; Pike et al., 2001). Surprisingly, ICI 182,780 (100 nM) alone potentiated EPSC amplitudes in 8 of 26 experiments. In 14 of these experiments (4 ICI responsive, 10 ICI nonresponsive), ICI 182,780 application was followed by E2 (100 nM), which induced no significant additional potentiation (Fig. $4 E$ ). Similar to E2 and DPN, ICI 182,780 decreased PPR in parallel with potentiating EPSC amplitude (Fig. 4I,J) (paired $t$ test, $p<0.05$ for responders; $p>0.3$ for nonresponders) and potentiated EPSCs in an input-specific manner ( 4 of 12 double-input experiments). The finding that ICI 182,780 alone can mimic and occlude acute effects of E2 on excitatory synaptic transmission suggests that $\operatorname{ER} \beta$ mediates acute E2induced EPSC potentiation without dimerizing.

Because ICI 182,780 has been reported to activate the G-protein-coupled membrane ER, GPR30 (Filardo et al., 2002), we also tested whether a selective agonist for GPR30, G-1, mimicked E2-induced EPSC potentiation, as has been suggested previously (Lebesgue et al., 2009). E2 and G-1 have similar binding affinities for GPR30 ( $K_{\mathrm{i}}$ of 5.7 and $11 \mathrm{nM}$, respectively) and 100 nM G-1 is sufficient to induce maximal $\mathrm{Ca}^{2+}$ mobilization in GPR30-transfected COS7 cells (Bologa et al., 2006). We found that G-1 (100 nM) potentiated EPSCs by $>20 \%$ in only 2 of 15 experiments, by 25 and 33\% (data not shown). G-1 decreased PPR in these experiments from 1.53 to 1.47 and 1.42 to 1.24 (data not shown). G-1 did not affect EPSC amplitude or PPR in the remaining 13 of 15 experiments. Thus, although we cannot exclude some role for GPR30 in EPSC potentiation, the small proportion of G-1-responsive experiments indicates that GPR30 is unlikely to fully account for EPSC potentiation by E2. The results with G-1 were in stark contrast to the effects DPN, which closely 
mimicked and occluded EPSC potentiation by $\mathrm{E} 2$, arguing that $\mathrm{E} 2$ acts primarily through ER $\beta$ to potentiate EPSCs.

Acute effects of $\mathrm{E} 2$ on the readily-releasable vesicle pool and individual vesicle release probability

To investigate the mechanism(s) of E2induced potentiation, we considered two major factors that influence glutamate release probability: the number of neurotransmitter vesicles in the RRP and the probability of release of an individual vesicle $\left(P_{\text {ves }}\right)$ from this pool. Long trains of high-frequency stimulation can be used to deplete the RRP (Schneggenburger et al., 1999). Steady-state release at the end of a train is related to the rate of vesicle replenishment. Assuming vesicle replenishment takes place at the same constant rate throughout the stimulus train, relative RRP size can be estimated by subtracting cumulative steady-state EPSC charge from cumulative EPSC charge recorded while the RRP empties, before the steady state is reached. Relative $P_{\text {ves }}$ can then be estimated as the fraction of the RRP released in response to the first pulse of the train (Wesseling and Lo, 2002).

Trains of EPSCs evoked by 100pulse, $20 \mathrm{~Hz}$ stimulation at the elevated temperature used for previous experiments $\left(32-35^{\circ} \mathrm{C}\right)$ failed to reach a steady state (data not shown), but trains evoked by identical stimulation at room temperature $\left(20-22^{\circ} \mathrm{C}\right)$ reached a steady state after $\sim 70$ pulses (Fig. $5 A$ ) (Wesseling and Lo, 2002; Garcia-Perez et al., 2008). The range of paired-pulse ratios at the two temperatures was comparable, consistent with others' findings that baseline release probability is unaffected by temperature (Allen and Stevens, 1994). Similarly, the effects of E2 (100 nM) at room temperature were similar to results at elevated temperature (supplemental Fig. S $3 A-D$, available at www.jneurosci.org as supplemental material). E2 increased EPSC amplitude at room temperature in 24 of 37 (65\%) experiments (normalized EPSC amplitude in E2 in responders, $1.38 \pm$ 0.04; normalized EPSC amplitude in E2 in nonresponders, $1.03 \pm 0.02$ ) and induced a robust decrease in PPR specifically in responders (supplemental Fig. $33 C, D$ ).

We then tested whether acute E2 effects on excitatory synaptic transmission are associated with changes in relative RRP size and/or relative $P_{\text {ves }}$ estimated using 100-pulse, $20 \mathrm{~Hz}$ stimulus trains at room temperature. The biggest effect of $\mathrm{E} 2$ was to increase the first few EPSCs in the train (Fig. $5 B, C$ ). Comparison of EPSC trains evoked before and during E2 application revealed no difference in cumulative steady-

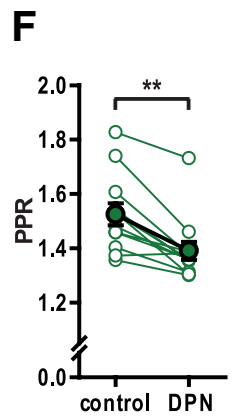

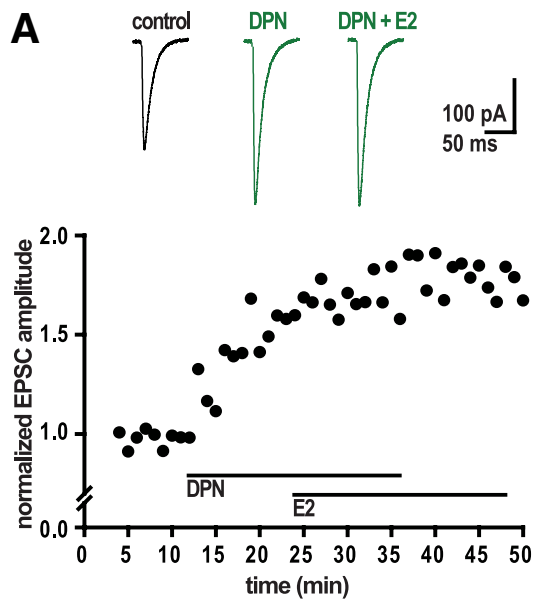
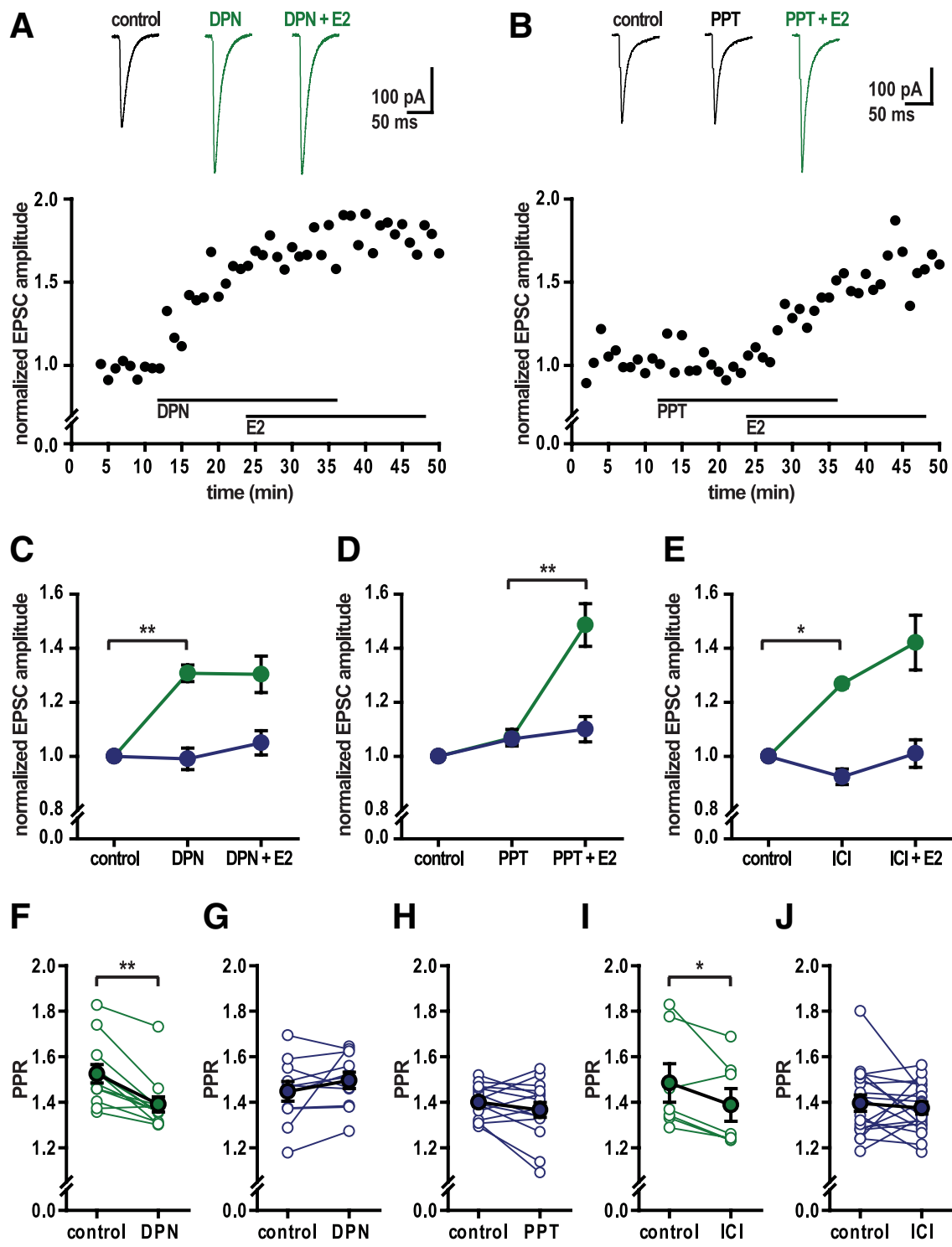

Figure 4. Estradiol-induced EPSC potentiation and PPR decrease are mediated by $\operatorname{ER} \beta$ and not ER $\alpha$. EPSCs were recorded during baseline and during bath application of ER $\beta$-selective agonist DPN (100 or $500 \mathrm{nM}$ ) followed by E2 (100 nM), during bath application of ER $\alpha$-selective agonist PPT (100 or $200 \mathrm{~nm}$ ) followed by E2 (100 nM), or during bath application of ER antagonist ICI 182,780 (100 nM) followed by E2 (100 nM).A, Representative experiment illustrating changes in EPSC amplitude during application of ER $\beta$ agonist DPN (500 $\mathrm{nm})$, followed by E2 (100 nM). Top, Representative individual traces from the same cell recorded in indicated conditions. $\boldsymbol{B}$, Representative experiment illustrating changes in EPSC amplitude during application of ER $\alpha$ agonist PPT (100 nм) followed by E2 (100 nM). Top, Representative individual traces from the same cell recorded in indicated conditions. C, Plot of mean \pm SEM normalized EPSC amplitude during baseline, in DPN, and DPN + E2 in DPN-responsive (green; $n=8$ ) and DPN-nonresponsive (blue; $n=7$ ) experiments. The ER $\beta$ agonist DPN mimicked and occluded EPSC potentiation by E2 (one-way ANOVA for responders, $p<0.01$ ). ${ }^{* *} p<0.01$ (significant difference between baseline and DPN, Bonferroni post hoc test). D, Plot of mean \pm SEM normalized EPSC amplitude during baseline, in PPT, and PPT + E2 in E2-responsive (green; $n=5$ ) and E2-nonresponsive (blue; $n=3$ ) experiments. In a subset of PPT-nonresponsive experiments, a subsequent response to E2 was observed (one-way ANOVA for responders, $p<0.01$ ). ${ }^{* *} p<0.01$ (significant difference between PPT and PPT + E2, Bonferroni posthoctest). E, Plot of mean \pm SEM normalized EPSC amplitude during baseline, in ICI 182,780, and ICI 182,780 + E2 in ICl-responsive (green; $n=4$ ) and ICl-nonresponsive (blue; $n=10$ ) experiments. ICI 182,780 mimicked and occluded EPSC potentiation by E2 (one-way ANOVA for responders, $p<0.01$ ). ${ }^{*} p<0.05$ (significant difference between baseline and ICI 182,780, Bonferronipost hoctest). $\boldsymbol{F}$, Plot of PPR in DPN-responsive experiments $(n=12)$. DPN decreased PPR in parallel with potentiating EPSCs. ${ }^{* *} p<0.01$ (paired ttest). G,Plot ofPPRin DPN-nonresponsive experiments $(n=11)$. Therewas no significant difference. $\boldsymbol{H}$, Plotof ofPRinall PPT experiments $(n=15)$. There wasno significantdifference.I,PlotofPPRin|CI-responsiveexperiments $(n=8)$.ICI 182,780 decreasedPPRinparallel with potentiating EPSCs. ${ }^{*} p<$ 0.05 (paired $t$ test).J, Plot of PPR in ICI-nonresponsive experiments $(n=18)$. There was no significant difference. In $\boldsymbol{F}-\boldsymbol{J}$, connected open symbols represent individual experiments; filled symbols represent the mean \pm SEM in each condition.

state EPSC charge between the two conditions (Fig. 5D) $(p>$ 0.2 ), suggesting that $\mathrm{E} 2$ does not modulate the steady-state rate of vesicle replenishment. Whereas there was a small increase in cumulative RRP charge in E2 (Fig. $5 E)(p<0.01)$, E2 caused a more 
A

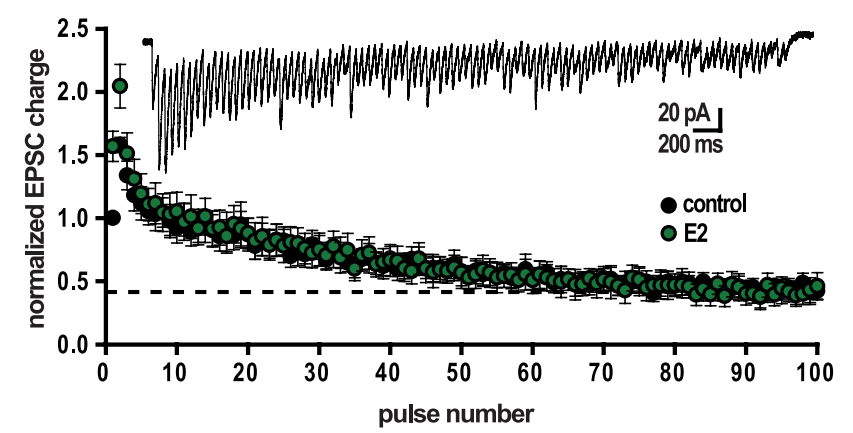

B

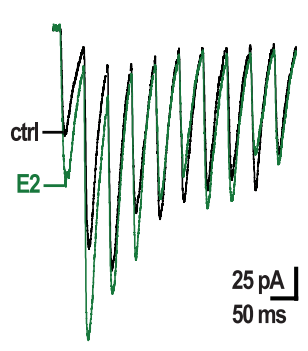

C
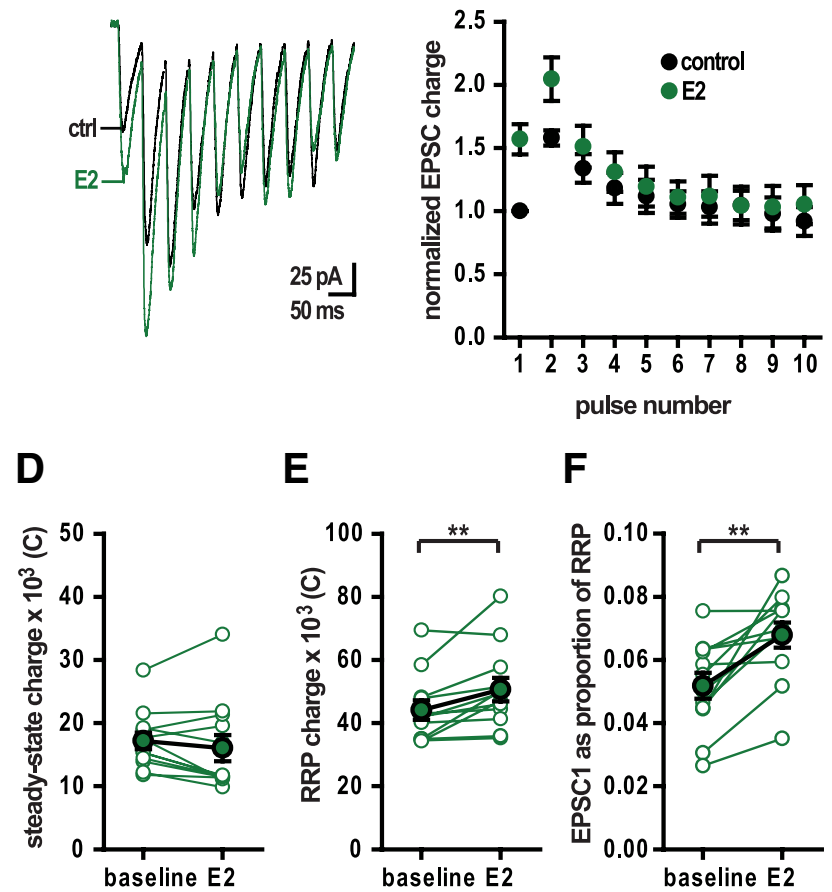

E

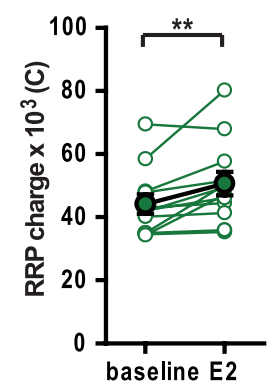

$\mathbf{F}$

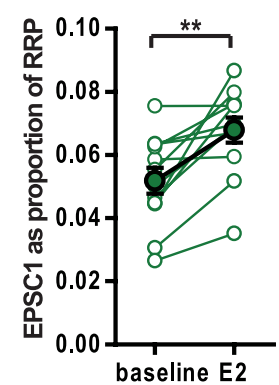

Figure 5. Acute effects of estradiol on the readily-releasable pool and individual vesicle release probability. Sizes of the RRP and individual $P_{\text {ves }}$ were estimated from responses to 100-pulse, $20 \mathrm{~Hz}$ stimulus trains during baseline and in the presence of $\mathrm{E} 2(100 \mathrm{nM})$. $\boldsymbol{A}$, Plot of mean \pm SEM normalized EPSC charge during stimulus trains during baseline (black) and in 100 nм E2 (green) in E2-responsive experiments ( $n=12$ ). Inset, Representative individual trace recorded during baseline. $\boldsymbol{B}$, Representative individual traces evoked by the first 10 pulses of a 100-pulse stimulus train, before and during E2. C, Plot of mean \pm SEM normalized EPSC charge during the first 10 pulses of 100-pulse stimulus trains during baseline and in $100 \mathrm{~nm}$ E2 $(n=12)$. D, Plot of cumulative steady-state charge (sum of pulses 81-100) before and during E2. There was no significant difference. $E$, Plot of RRP charge [(sum of pulses $1-80)-4 \times$ (sum of pulses 81-100)] before and during E2. ${ }^{* *} p<0.01$ (significant effect of E2; paired $t$ test). $\boldsymbol{F}$, Plot of EPSC1 charge as proportion of RRP charge before and during E2. E2 consistently increased the proportion of RRP released by the first stimulus, consistent with increasing $P_{\text {ves }}{ }^{* *} p<0.01$ (significant effect of E2; paired $t$ test). For $\mathbf{D}-\boldsymbol{F}$, connected open symbols represent individual experiments; filled symbols represent the mean $\pm \mathrm{SEM}$ in each condition. See also supplemental Figure S3 (available at www.jneurosci.org as supplemental material).

robust increase in the fraction of the RRP released in response to the first pulse, indicating an increase in $P_{\text {ves }}$ (Fig. $\left.5 F\right)(p<0.01)$. Furthermore, examining individual experiments showed that E2induced EPSC potentiation was correlated with the increase in $P_{\text {ves }}$, but not in the RRP. There was no correlation between the relative change in RRP and E2-induced EPSC potentiation (supplemental Fig. S3E) $(r=0.3597 ; p>0.1)$. In contrast, a large relative change in $P_{\text {ves }}$ was consistently associated with greater
EPSC potentiation by E2 and vice versa (supplemental Fig. S3F) $(r=0.7136 ; p<0.01)$. This observation, and the fact that the magnitude of the $P_{\text {ves }}$ increase in E2 $(36 \pm 9 \%)$ was similar to the degree of EPSC potentiation ( $38 \pm 4 \%$ ), suggests that E2 potentiates EPSC amplitude primarily by increasing individual vesicle release probability.

E2 increases average cleft glutamate concentration, suggesting enhanced multivesicular release

Increased $P_{\text {ves }}$ could result in a larger fraction of stimulated synapses releasing a single vesicle and/or cause some synapses to release more than one vesicle upon stimulation, i.e., multivesicular release (MVR). Compared to single-vesicle release, MVR leads to higher glutamate concentration in the synaptic cleft after stimulation. Evidence for MVR has come from experiments using low-affinity glutamate receptor antagonists that block EPSCs in a manner dependent on cleft glutamate concentration. Manipulations known to increase $P_{\text {ves}}$, such as elevated extracellular $\mathrm{Ca}^{2+}$ or 4-AP, increase average cleft glutamate concentration, whereas manipulations that decrease $P_{\text {ves }}$, such as adenosine, have the opposite effect, consistent with changes in $P_{\text {ves }}$ being related to changes in MVR (Tong and Jahr, 1994; Christie and Jahr, 2006). Based on these studies, we hypothesized that acute E2 application, which we found increases $P_{\mathrm{ves}}$, might enhance MVR, resulting in higher average cleft glutamate concentration.

We used $\gamma \mathrm{DGG}(1 \mathrm{mM})$, a low-affinity AMPA receptor antagonist, to investigate whether E2-induced EPSC potentiation is associated with a higher average cleft glutamate concentration. If so, the degree of EPSC block by $\gamma$ DGG should be smaller in the presence than in the absence of E2. Because of the lifetime of a recording, it was not feasible to examine the degree of $\gamma \mathrm{DGG}$ block both before and after E2 application for the same cells. Instead, we examined $\gamma$ DGG block in the absence of E2 (Fig. 6A) in one group of cells and in the presence of E2 (Fig. $6 B$ ) in a separate group of cells. In experiments where $\gamma \mathrm{DGG}$ was applied in the absence of E2, E2 was applied after $\gamma \mathrm{DGG}$ washout to determine whether the stimulated inputs were $\mathrm{E} 2$ responsive or nonresponsive (Fig. 6A). In agreement with the MVR hypothesis, E2 decreased $\gamma$ DGG block (corresponding to a larger fraction of the EPSC remaining in $\gamma \mathrm{DGG}$ ), indicating higher average cleft glutamate concentration in E2 (Fig. $6 E$ ) ( $t$ test, $p<0.05$ ). Importantly, this was true only in E2-responsive experiments and not in E2-nonresponsive experiments (data not shown) ( $t$ test, $p>0.3$ ), demonstrating that the E2-induced increase in cleft glutamate concentration is specifically associated with E2-induced EPSC potentiation. The magnitude of E2's effect on $\gamma$ DGG block is comparable to the effect of increasing extracellular $\mathrm{Ca}^{2+}$ from 1.5 to $2.5 \mathrm{~mm}$ (Christie and Jahr, 2006), a manipulation known to significantly influence neurotransmitter release. To confirm that the difference between the degree of $\gamma$ DGG block in the absence versus presence of $\mathrm{E} 2$ in responders was not caused by voltageclamp error, we repeated this experiment with NBQX (200 $\mathrm{nM}$ ), a high-affinity AMPA receptor antagonist for which block is independent of cleft glutamate concentration (Fig. $6 D-F)$. As expected, and unlike $\gamma$ DGG block, the degree of NBQX block was the same in the presence and absence of E2 (Fig. 6F) ( $t$ test, $p>0.4$ ). Thus, these results show that E2 increases average cleft glutamate concentration, which, together with our result that E2 increases $P_{\text {ves }}$ (Fig. $5 F$ ), strongly suggests that E2 enhances MVR.

Finally, we asked whether E2 could occlude the effect of a manipulation known to increase MVR. Paired-pulse facilitation is related mostly to higher $P_{\text {ves }}$ on the second pulse in a pair 

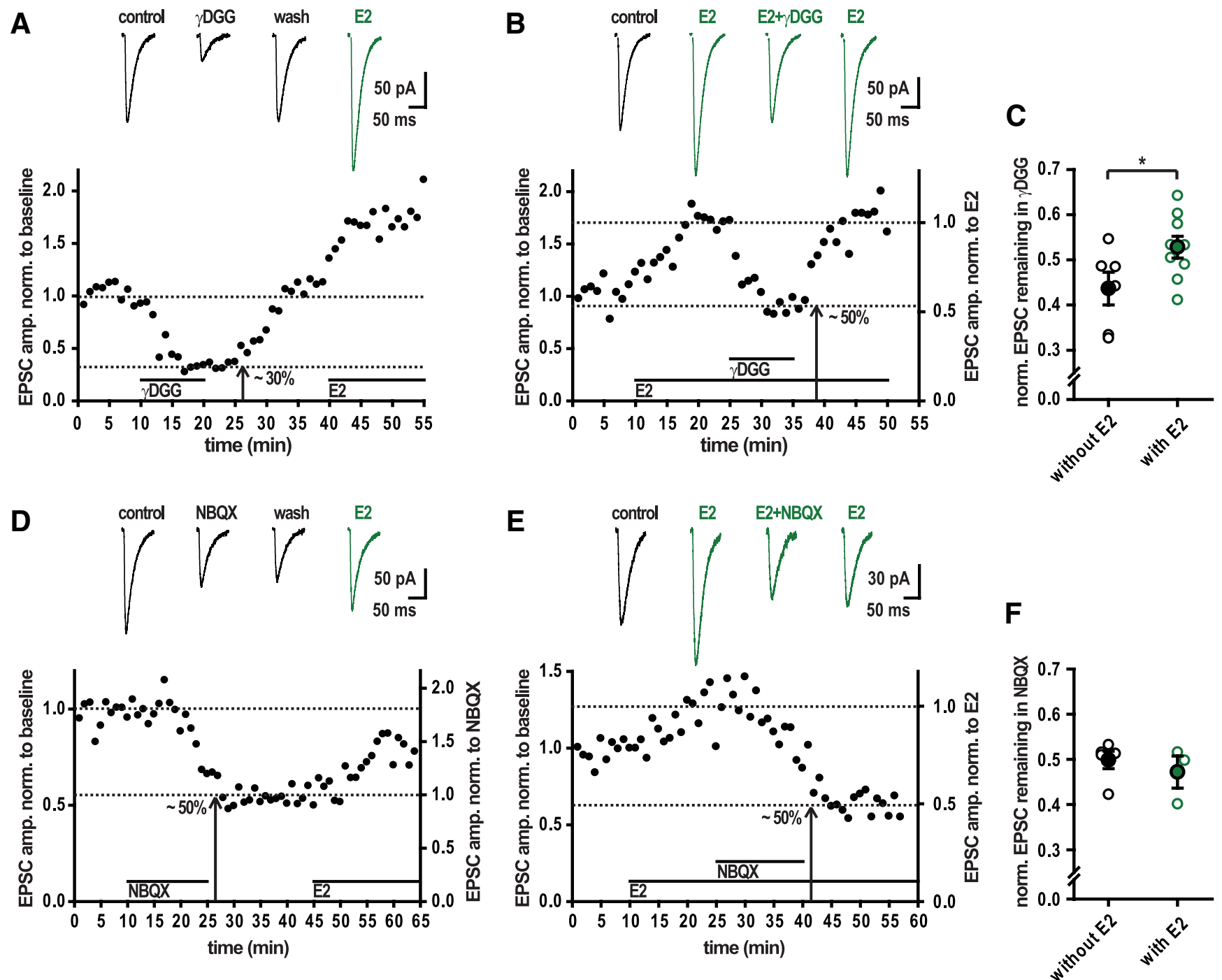

Figure 6. Estradiol increases average cleft glutamate concentration. $A-C$, The low-affinity AMPAR antagonist $\gamma D G G(1 \mathrm{~mm})$ was bath applied either in the absence or in the presence of E2 (100 nм). A, Representative experiment illustrating changes in EPSC amplitude during application of $\gamma D G G$ in the absence of E2. E2 was applied at the end of the experiment to confirm that the stimulated inputs were E2 responsive. Top, Individual current traces from the same cell recorded in indicated conditions. $\boldsymbol{B}$, Representative experiment illustrating changes in EPSC amplitude during application of $\gamma D G G$ in the presence of E2. Top, Individual current traces from the same cell recorded in indicated conditions. $C$, Plot of normalized EPSC amplitude remaining in $\gamma D G G$ in the absence $(n=6)$ versus in the presence $(n=9)$ of $E 2$. $\gamma D G G$ was less effective in the presence of $E 2$, consistent with higher average cleft glutamate concentration in E2. ${ }^{*} p<0.05$ (a significant effect of E2; $t$ test). $\boldsymbol{D}-\boldsymbol{F}$, The high-affinity AMPAR antagonist NBQX (200 nM) was bath applied either in the absence or in the presence of E2 (100 nм). D, Representative experiment illustrating changes in EPSC amplitude during application of NBQX in the absence of E2. E2 was applied at the end of the experiment to confirm that the stimulated inputs were E2 responsive. Top, Individual current traces from the same cell recorded in indicated conditions. $E$, Representative experiment illustrating changes in EPSC amplitude during application of NBQX in the presence of E2. Top, Individual current traces from the same cell recorded in indicated conditions. $\boldsymbol{F}$, Plot of normalized EPSC amplitude remaining in NBQX in the absence $(n=5)$ versus in the presence $(n=3)$ of E2. There was no significant difference. For $\boldsymbol{C}$ and $\boldsymbol{F}$, open symbols represent individual experiments; filled symbols represent the mean \pm SEM in each condition.

because of residual presynaptic $\mathrm{Ca}^{2+}$ during the second pulse. Others have shown that increased $P_{\text {ves }}$ on the second pulse increases MVR, as indicated by less $\gamma$ DGG block of the second EPSC in a pair and therefore a higher PPR in $\gamma$ DGG (Christie and Jahr, 2006). If $\mathrm{E} 2$ increases $P_{\text {ves }}$ and MVR by enhancing presynaptic $\mathrm{Ca}^{2+}$ influx, it might occlude MVR on the second pulse in a pair, and thus the ability of $\gamma$ DGG to increase PPR. Alternatively, if $\mathrm{E} 2$ promotes glutamate release through a mechanism other than by increasing presynaptic $\mathrm{Ca}^{2+}$, the effect of $\gamma \mathrm{DGG}$ on PPR should be similar in the absence and presence of E2.

We first evaluated the effect of $\gamma$ DGG on paired EPSCs and PPR (IPI, $50 \mathrm{~ms}$ ) in the absence of E2 (Fig. 7A) and confirmed that $\gamma$ DGG blocks the second EPSC in a pair to a lesser extent than the first, resulting in an increase in PPR (Fig. $7 C, D$ ). Then we tested whether E2 could occlude the effect of $\gamma$ DGG on paired EPSCs and PPR (Fig. 7B). This showed that in the presence of E2, $\gamma$ DGG block of the second EPSC was still less than block of the first EPSC (Fig. 7C) (two-way ANOVA, interaction, $p>0.4$ ). As a result, $\gamma$ DGG increased PPR similarly in the absence and presence of E2, by $11 \pm 7 \%$ versus $11 \pm 3 \%$, respectively (Fig. $7 D$ ) (two-way ANOVA, interaction, $p>0.7$ ). This indicates that although $\mathrm{E} 2$ increases average cleft glutamate concentration during the first pulse, glutamate concentration increases even further on the second pulse. As with single-pulse $\gamma$ DGG experiments, we excluded a possible contribution of voltage-clamp error by showing that the two EPSCs in a pair were blocked equally by NBQX, both in the absence and presence of $\mathrm{E} 2$, resulting in no change in PPR in NBQX (Fig. 7E-H). Thus, these experiments demon- 
A

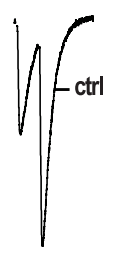

E

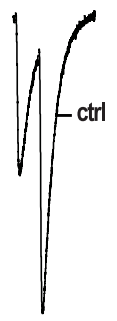

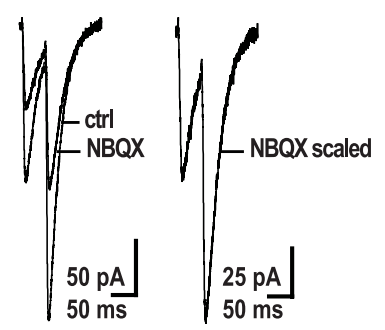

B

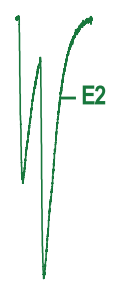

F

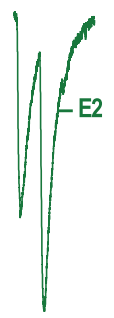

F
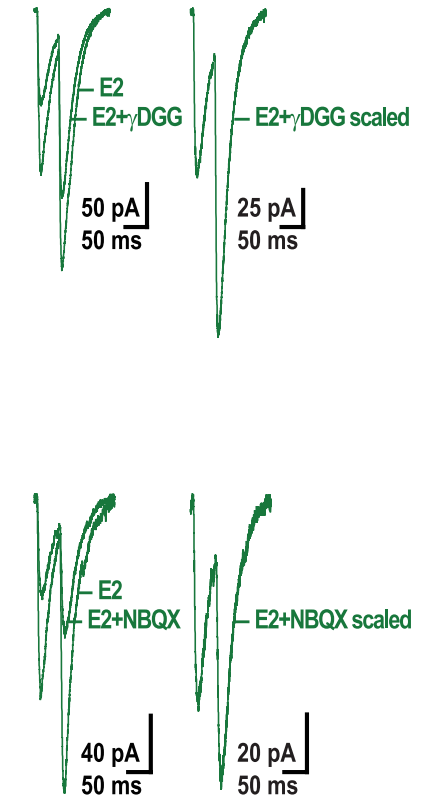

C

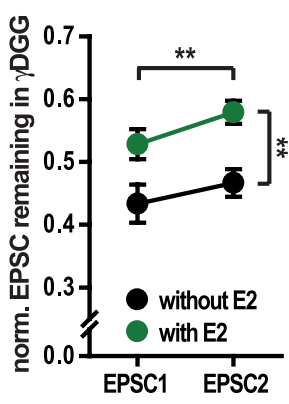

G

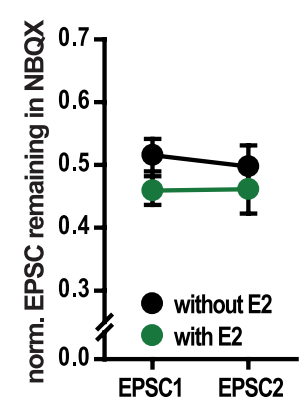

D

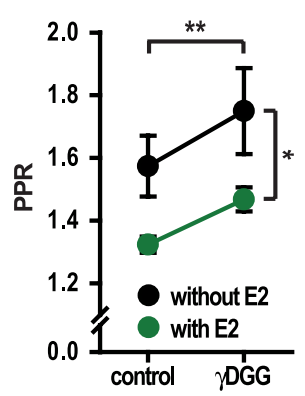

H

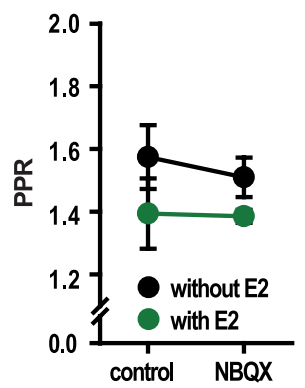

Figure 7. Estradiol does not occlude the effect of paired-pulse facilitation to increase average cleft glutamate concentration. EPSCs were evoked by paired-pulse stimulation (interpulse interval, $50 \mathrm{~ms}) . \boldsymbol{A}-\boldsymbol{D}$, The low-affinity AMPAR antagonist $\gamma D \mathrm{DG}(1 \mathrm{~mm})$ was bath applied either in the absence or in the presence of E2 $(100 \mathrm{~nm}) . A$, Representative individual traces recorded before and in $\gamma D G G$ in the absence of E2. $B$, Representative individual traces recorded before and in $\gamma D G G$ in the presence of E2. C, Plot of mean \pm SEM normalized EPSC 1 and EPSC 2 amplitudes remaining in $\gamma D G G$ in the absence $(n=6)$ versus in the presence $(n=9)$ of E2. Paired-pulse facilitation decreased the degree of EPSC block by $\gamma D G G$ similarly in the absence and presence of E2 (two-way ANOVA). ${ }^{* *} p<0.01$ (a significant effect of EPSC number and a significant effect of E2); $p>0.4$ (interaction). $\boldsymbol{D}$, Plot of mean \pm SEM PPR before and in $\gamma D G G$ in the absence $(n=6)$ versus in the presence $(n=9)$ of E2 (two-way ANOVA). $\gamma D \mathrm{DG}$ increased PPR similarly in the absence and presence of E2. ${ }^{* *} p<0.01$ (significant effect of $\gamma D \mathrm{DG}$ ); ${ }^{*} p<0.05$ (significant effect of E2); $p>0.7$ (interaction). $\boldsymbol{E}-\boldsymbol{H}$, The high-affinity AMPAR antagonist NBQX $(200 \mathrm{~nm})$ was bath applied either in the absence or in the presence of E2 $(100 \mathrm{~nm})$. $\boldsymbol{E}$, Representative individual traces recorded before and in NBQX in the absence of E2. $\boldsymbol{F}$, Representative individual traces recorded before and in NBQX in the presence of E2. G, Plot of mean \pm SEM normalized EPSC1 and EPSC2 amplitudes remaining in NBQX in the absence $(n=5)$ versus in the presence $(n=3)$ of E2. There was no significant difference. $\boldsymbol{H}$, Plot of mean \pm SEM PPR before and in NBQX in the absence $(n=5)$ versus in the presence $(n=$ 3) of E2. There was no significant difference.

strated that the E2-induced increase in cleft glutamate concentration, assayed by $\gamma \mathrm{DGG}$ block, is additive with the increase caused by paired-pulse facilitation.

The failure of E2 to occlude $\gamma$ DGG's effect on PPR is in contrast to the effect of increasing $P_{\text {ves }}$ by elevating extracellular $\mathrm{Ca}^{2+}$. Elevating $\mathrm{Ca}^{2+}$ from 1.5 to $2.5 \mathrm{~mm}$ partially occludes the ability of paired-pulse facilitation to increase cleft glutamate concentration further (Christie and Jahr, 2006), presumably because both manipulations increase $P_{\text {ves }}$ through the same mechanism, increased presynaptic $\mathrm{Ca}^{2+}$ concentration. Our observation that E2 does not occlude $\gamma$ DGG's effect on PPR suggests that the increase in $P_{\text {ves }}$ and enhanced MVR attributable to E2 likely involves a factor(s) other than increased presynaptic $\mathrm{Ca}^{2+}$ influx. For example, E2 may increase $P_{\text {ves }}$ and MVR by mobilizing vesicles closer to sites of $\mathrm{Ca}^{2+}$ influx and/or by increasing $\mathrm{Ca}^{2+}$ sensitivity of vesicle release machinery. These possibilities are especially intriguing in light of reports of synaptic-vesicleassociated estrogen receptors (Milner et al., 2001, 2005; Hart et al., 2007), whose function is currently unknown.

\section{Discussion}

We find that E2 acutely potentiates excitatory synaptic transmission in the hippocampus through a presynaptic mechanism, by increasing the probability of glutamate release at synapses with a relatively low initial release probability. This effect is mediated by $\mathrm{ER} \beta$, not $\mathrm{ER} \alpha$, and is mimicked by ICI 182,780 , indicating that $\mathrm{ER} \beta$ acts as a monomer. We further show that E2 increases glu- tamate release primarily by increasing individual vesicle release probability and that it increases average cleft glutamate concentration, which together argue strongly that E2 enhances multivesicular release. The concentration dependence and time course of acute EPSC potentiation suggest that locally synthesized neurosteroid E2, not ovarian E2, may activate this effect in vivo.

E2 acutely decreases PPR in parallel with potentiating EPSCs Previous studies suggested that E2 exerts its acute effect(s) by enhancing postsynaptic sensitivity to glutamate in a subset of cells (Wong and Moss, 1992; Gu and Moss, 1996). We find instead that E2 sensitivity is input specific, rather than cell specific; inputs characterized by relatively high initial PPR (low probability of release) are those at which E2 subsequently potentiates EPSCs. Also in contrast with previous studies, but consistent with a presynaptic effect, E2 decreases PPR in parallel with increasing EPSC amplitude.

Our experiments differed from previous studies in several ways. Perhaps most importantly, we explicitly considered heterogeneity of E2 responsiveness. By dividing inputs into E2 responsive and E2 nonresponsive, we were able to detect a change in PPR specifically in E2-responsive inputs. Previous studies that evaluated PPR without separating E2-responsive and E2-nonresponsive inputs used 100 pM (Kim et al., 2006) or 1 nM E2 (Foy et al., 1999; Kramar et al., 2009). Considering the subset of our experiments with these concentrations, the increase in EPSC amplitude for E2-responsive and E2-nonresponsive inputs together was statistically significant, whereas the decrease in 
PPR was not. Additionally, particularly for previous studies with dissociated cells (Gu and Moss, 1996), it is possible that agonist application activated primarily extrasynaptic receptors, which may not accurately reflect properties of synaptic transmission. Finally, although our results strongly support a presynaptic mechanism for synaptic potentiation by E2, they do not exclude the possibility that E2 also increases postsynaptic sensitivity to glutamate.

\section{E2 enhances glutamate release primarily by increasing $P_{\text {ves }}$}

We used high-frequency stimulus trains to investigate the mechanism(s) by which E2 enhances glutamate release. We found a small increase in cumulative release during a train, indicating increased RRP size, and a stronger effect on the fraction of the RRP released by the first pulse, indicating increased $P_{\text {ves }}$. Although it is possible that E2 increases both the RRP and $P_{\text {ves }}$ in parallel, a more parsimonious explanation is that increased $P_{\text {ves }}$ accounts for both observations.

Although the RRP has been functionally defined as cumulative release during various depletion protocols, including stimulus trains (Stevens and Tsujimoto, 1995; Rosenmund and Stevens, 1996; Wesseling and Lo, 2002), release during a train is influenced by factors in addition to how many vesicles are available for release at the beginning of stimulation. For example, a common assumption in estimating the RRP from trains is that the rate of vesicle replenishment during the train is constant as estimated from steady-state charge (Schneggenburger et al., 1999). However, there is evidence that the rate of replenishment increases in a $\mathrm{Ca}^{2+}$-dependent manner during the first $10-20$ pulses, reaching an elevated level that persists for the rest of the train (Stevens and Wesseling, 1998; Wesseling and Lo, 2002). A change in the time course of such activity-dependent upregulation of vesicle replenishment could result in more total vesicles released during the train and a larger RRP estimate. Second, the identity/properties of vesicles constituting RRP may vary under different conditions. For example, under conditions of increased $P_{\text {ves}}$, additional, "reluctant" vesicles may be released during a train, resulting in a larger RRP estimate (Moulder and Mennerick, 2005). These considerations suggest that E2 could increase both the RRP estimate and $P_{\text {ves }}$ by a single mechanism. For example, E2 could elevate intracellular $\mathrm{Ca}^{2+}$, mobilize vesicles closer to $\mathrm{Ca}^{2+}$ sources, or upregulate one of the biochemical steps in the release process, any of which could result in higher $P_{\text {ves}}$, faster vesicle replenishment, and/or release of additional, "reluctant" vesicles.

\section{E2 promotes multivesicular release}

The observation that E2 consistently and robustly increased $P_{\text {ves }}$ suggested that E2 might promote MVR. The possibility and physiological significance of MVR at hippocampal synapses has been questioned based on minimal stimulation experiments (Stevens and Wang, 1995) and estimates of glutamate receptor saturation after release of a single vesicle (Clements et al., 1992). However, other studies suggest that MVR does occur, particularly under conditions of elevated $P_{\text {ves }}$ (Tong and Jahr, 1994; Oertner et al., 2002; Christie and Jahr, 2006), and argue that glutamate receptors are not saturated by a single vesicle (Liu et al., 1999; McAllister and Stevens, 2000). Although evidence for MVR in the immature hippocampus is growing, no studies to date have reported MVR in the adult.

We used the low-affinity AMPAR antagonist $\gamma$ DGG to compare relative cleft glutamate concentration in the presence versus absence of E2. We found that $\gamma$ DGG blocked EPSCs less effectively in E2, indicating that E2 increases average cleft glutamate concentration. Although there are several mechanisms by which E2 could increase cleft glutamate concentration, MVR is the most likely. One alternative is that E2 downregulates astrocytic glutamate uptake, resulting in increased spillover. This is unlikely, however, because glutamate uptake is extremely efficient (Diamond and Jahr, 2000), such that even when it is pharmacologically reduced, the degree of $\gamma \mathrm{DGG}$ block of EPSCs remains unaffected (Christie and Jahr, 2006). E2 also could increase cleft glutamate by causing faster or more complete vesicle emptying. This too is unlikely, as it should result in faster EPSC rise times in E2 (Choi et al., 2000), which we did not observe. Thus, the best explanation for our findings that E2 increases both $P_{\text {ves }}$ and average cleft glutamate concentration is that E2 increases MVR. To our knowledge, this is the first demonstration of MVR in adult hippocampus. Furthermore, our observation that the increase in cleft glutamate attributable to E2 fails to occlude the increase attributable to paired-pulse facilitation suggests that E2 may enhance MVR by a mechanism other than elevating presynaptic $\mathrm{Ca}^{2+}$. This finding argues for the possibility that E2 mobilizes vesicles toward sites of $\mathrm{Ca}^{2+}$ influx and/or regulates vesicle release machinery.

\section{Rapid E2 signaling}

In neurons, E2 acutely increases $\mathrm{Ca}^{2+}$ influx through L-type $\mathrm{Ca}^{2+}$ channels and activates protein kinases including $\mathrm{Src}$, Erk1/2, CaMKII, and protein kinase A (Gu and Moss, 1996; Lee et al., 2004; Wu et al., 2005). Most of these effects are mediated by classical ERs acting outside the nucleus (Wade and Dorsa 2003; Wu et al., 2005; Zhao and Brinton 2007), but neither the initial steps of extranuclear ER activation, nor the consequences of rapid E2 signaling are well understood.

We found that E2-induced EPSC potentiation is mimicked by both an ER $\beta$ agonist and ICI 182,780. ICI compounds interfere with ER dimerization (Fawell et al., 1990; Pike et al., 2001), and consequently block classical nuclear ER activity (Sun et al., 2002). In contrast, rapid E2 signaling is less consistently blocked by ICI compounds (Singh et al., 1999) and may even be activated by them (Zhao et al., 2006). Our results are consistent with these latter reports, and suggest that $\operatorname{ER} \beta$ acts as a monomer to activate acute EPSC potentiation.

Interestingly, targets of E2-activated kinases include synaptic vesicle proteins critical for vesicle mobilization and $\mathrm{Ca}^{2+}$ dependent release (Hilfiker et al., 1999; Chi et al., 2003; Kushner et al., 2005; Menegon et al., 2006; Onofri et al., 2007), suggesting that E2 could enhance release by regulating synaptic vesicle proteins. If E2 initiates a cascade of molecular events leading to enhanced vesicular release, such as vesicle protein phosphorylation, this may explain our observation that EPSC potentiation persisted after E2 washout. Since EM immunocytochemical studies have found ER $\beta$ in presynaptic boutons in CA1 (Milner et al., 2005), exploring the possibility that E2 acts via vesicle-associated ERs to regulate synaptic vesicle proteins will be an important area of future research.

\section{A possible role for neurosteroid E2}

Although EPSC potentiation occurred with 100 pM E2, the effect was more robust at higher than circulating E2 concentrations. Additionally, the time course of E2-induced EPSC potentiation is faster than fluctuations in circulating $\mathrm{E} 2$ in vivo. These issues raise the question of whether acute E2-induced EPSC potentiation occurs physiologically. Importantly, recent studies show that the hippocampus can generate neurosteroid E2, resulting in high local E2 concentrations that can change rapidly (Hojo et al., 2004, 
2009). Additionally, EM immunocytochemistry shows that aromatase, the rate-limiting enzyme in E2 synthesis, is present both presynaptically and postsynaptically at a subset of synapses in hippocampal CA1 (Hojo et al., 2004). Together, these findings suggest that neurosteroid E2 could activate EPSC potentiation in vivo. Indeed, the concentration dependence of EPSC potentiation likely protects hippocampal synaptic transmission from modulation by the relatively slow and low amplitude fluctuations in circulating E2 from the ovaries. Thus, neurosteroid E2 may interact with presynaptic $\operatorname{ER} \beta$ to activate a distinct suite of cellular/molecular events that increase glutamate release resulting in rapid, input-specific potentiation of hippocampal synaptic transmission.

\section{References}

Allen C, Stevens CF (1994) An evaluation of causes for unreliability of synaptic transmission. Proc Natl Acad Sci U S A 91:10380-10383.

Bologa CG, Revankar CM, Young SM, Edwards BS, Arterburn JB, Kiselyov AS, Parker MA, Tkachenko SE, Savchuck NP, Sklar LA, Oprea TI, Prossnitz ER (2006) Virtual and biomolecular screening converge on a selective agonist for GPR30. Nat Chem Biol 2:207-212.

Chi P, Greengard P, Ryan TA (2003) Synaptic vesicle mobilization is regulated by distinct synapsin I phosphorylation pathways at different frequencies. Neuron 38:69-78.

Choi S, Klingauf J, Tsien RW (2000) Postfusional regulation of cleft glutamate concentration during LTP at "silent synapses." Nat Neurosci 3:330-336.

Christie JM, Jahr CE (2006) Multivesicular release at Schaffer collateralCA1 hippocampal synapses. J Neurosci 26:210-216.

Clements JD, Lester RA, Tong G, Jahr CE, Westbrook GL (1992) The time course of glutamate in the synaptic cleft. Science 258:1498-1501.

Corpechot C, Robel P, Axelson M, Sjovall J, Baulieu E-E (1981) Characterization and measurement of dehydroepiandrosterone sulfate in rat brain. Proc Natl Acad Sci U S A 78:4704-4707.

Diamond JS, Jahr CE (2000) Synaptically released glutamate does not overwhelm transporters on hippocampal astrocytes during high-frequency stimulation. J. Neurophysiol 83:2835-2843.

Dobrunz LE, Stevens CF (1997) Heterogeneity of release probability, facilitation, and depletion at central synapses. Neuron 18:995-1008.

Fawell SE, White R, Hoare S, Sydenham M, Page M, Parker MG (1990) Inhibition of estrogen receptor-DNA binding by the "pure" antiestrogen ICI 164,384 appears to be mediated by impaired receptor dimerization. Proc Natl Acad Sci U S A 87:6883-6887.

Filardo EJ, Quinn JA, Frackelton AR Jr, Bland KI (2002) Estrogen action via the G protein-coupled receptor, GPR30: Stimulation of adenyl cyclase and cAMP-mediated attenuation of the epidermal growth factor receptor-to-MAPK signaling axis. Mol Endocrinol 16:70-84.

Foy MR, Xu J, Xie X, Brinton RD, Thompson RF, Berger TW (1999) $17 \beta$ estradiol enhances NMDA receptor-mediated EPSPs and long-term potentiation. J Neurophysiol 81:925-929.

Garcia-Perez E, Lo DC, Wesseling JF (2008) Kinetic isolation of a slowly recovering component of short-term depression during exhaustive use at excitatory hippocampal synapses. J Neurophysiol 100:781-795.

Gu Q, Moss RL (1996) $17 \beta$-estradiol potentiates kainate-induced currents via activation of the cAMP cascade. J Neurosci 16:3620-3629.

Gu Q, Moss RL (1998) Novel mechanism for non-genomic action of $17 \beta$ oestradiol on kainate-induced currents in isolated rat CA1 hippocampal neurones. J Physiol 506:745-754.

Hart SA, Snyder MA, Smejkalova T, Woolley CS (2007) Estrogen mobilizes a subset of estrogen receptor- $\alpha$-immunoreactive vesicles in inhibitory presynaptic boutons in hippocampal CA1. J Neurosci 27:2102-2111.

Hilfiker S, Pieribone VA, Nordstedt C, Greengard P, Czernik AJ (1999) Regulation of synaptotagmin I phosphorylation by multiple protein kinases. J Neurochem 73:921-932.

Hjelmstad GO, Isaac JT, Nicoll RA, Malenka RC (1999) Lack of AMPA receptor desensitization during basal synaptic transmission in the hippocampal slice. J Neurophysiol 81:3096-3099.

Hojo Y, Hattori T, Enami T, Furukawa A, Suzuki K, Ishii H, Mukai H, Morrison JH, Janssen WGM, Kominami S, Harada N, Kimoto T, Kawato S (2004) Adult male rat hippocampus synthesizes estradiol from pregnenolone by cytochromes P45017 $\alpha$ and P450 aromatase localized in neurons. Proc Natl Acad Sci U S A 101:865-870.
Hojo Y, Higo S, Ishii H, Ooishi Y, Mukai H, Murakami G, Kominami T, Kimoto T, Honma S, Poirier D, Kawato S (2009) Comparison between hippocampus-synthesized and circulation-derived sex steroids in the hippocampus. Endocrinology 150:5106-5112.

Kim MT, Soussou W, Gholmieh G, Ahuja A, Tanguay A, Berger TW, Brinton RD (2006) $17 \beta$-estradiol potentiates field excitatory postsynaptic potentials within each subfield of the hippocampus with greatest potentiation of the associational/commissural afferents of CA3. Neuroscience 141:391-406.

Kimoto T, Tsurugizawa T, Ohta Y, Makino J, Tamura H, Hojo Y, Takata N, Kawato S (2001) Neurosteroid synthesis by cytochrome P450-containing systems localized in the rat brain hippocampal neurons: N-methyl-Daspartate and calcium-dependent synthesis. Endocrinology 142:3578-3589.

Kramar EA, Chen LY, Brandon NJ, Rex CS, Liu F, Gall CM, Lynch G (2009) Cytoskeletal changes underlie estrogen's acute effects on synaptic transmission and plasticity. J Neurosci 29:12982-12993.

Kushner SA, Elgersma Y, Murphy GG, Jaarsma D, van Woerden GM, Hojjati MR, Cui Y, LeBoutillier JC, Marrone DF, Choi ES, De Zeeuw CI, Petit TL, Pozzo-Miller L, Silva AJ (2005) Modulation of presynaptic plasticity and learning by the h-ras/extracellular signal-regulated kinase/synapsin I signaling pathway. J Neurosci 25:9721-9734.

Lebesgue D, Chevaleyre V, Zukin RS, Etgen AM (2009) Estradiol rescues neurons from global ischemia-induced cell death: multiple cellular pathways of neuroprotection. Steroids 74:555-561.

Lee SJ, Campomanes CR, Sikat PT, Greenfield AT, Allen PB, McEwen BS (2004) Estrogen induces phosphorylation of cyclic AMP response element binding (pCREB) in primary hippocampal cells in a time-dependent manner. Neuroscience 124:549-560.

Liu G, Choi S, Tsien RW (1999) Variability of neurotransmitter concentration and nonsaturation of postsynaptic AMPA receptors at synapses in hippocampal cultures and slices. Neuron 22:395-409.

Malinow R, Tsien RW (1990) Presynaptic enhancement shown by wholecell recordings of long-term potentiation in hippocampal slices. Nature 346:177-180.

McAllister AK, Stevens CF (2000) Nonsaturation of AMPA and NMDA receptors at hippocampal synapses. Proc Natl Acad Sci USA 97:6173-6178.

Menegon A, Bonanomi D, Albertinazzi C, Lotti F, Ferrari G, Kao H-T, Benfenati F, Baldelli P, Valtorta F (2006) Protein kinase A-mediated synapsin I phosphorylation is a central modulator of $\mathrm{Ca}^{2+}$-dependent synaptic activity. J Neurosci 26:11670-11681.

Meyers MJ, Sun J, Carlson KE, Marriner GA, Katzenellenbogen BS, Katzenellenbogen JA (2001) Estrogen receptor- $\beta$ potency-selective ligands: structure-activity relationship studies of diarylpropionitriles and their acetylene and polar analogues. J Med Chem 44:4230-4251.

Milner TA, McEwen BS, Hayashi S, Li CJ, Reagan LP, Alves SE (2001) Ultrastructural evidence that hippocampal alpha estrogen receptors are located at extranuclear sites. J Comp Neurol 429:355-371.

Milner TA, Ayoola K, Drake CT, Herrick SP, Tabori NE, McEwen BS, Warrier S, Alves SE (2005) Ultrastructural localization of estrogen receptor $\beta$ immunoreactivity in the rat hippocampal formation. J Comp Neurol 491:81-95.

Moulder KL, Mennerick S (2005) Reluctant vesicles contribute to the total readily releasable pool in glutamatergic hippocampal neurons. J Neurosci 25:3842-3850.

Oertner TG, Sabatini BL, Nimchinsky EA, Svoboda K (2002) Facilitation at single synapses probed with optical quantal analysis. Nat Neurosci 5:657-664

Onofri F, Messa M, Matafora V, Bonanno G, Corradi A, Bachi A, Valtorta F, Benfenati F (2007) Synapsin phosphorylation by src tyrosine kinase enhances src activity in synaptic vesicles. J Biol Chem 282:15754-15767.

Pike ACW, Brzozowski AM, Walton J, Hubbard RE, Thorsell A-G, Li Y-L, Gustafsson J-A, Carlquist M (2001) Structural insights into the mode of action of a pure antiestrogen. Structure 9:145-153.

Rosenmund C, Stevens CF (1996) Definition of the readily releasable pool of vesicles at hippocampal synapses. Neuron 16:1197-1207.

Rudick CN, Woolley CS (2003) Selective estrogen receptor modulators regulate phasic activation of hippocampal CA1 pyramidal cells by estrogen. Endocrinology 144:179-187.

Schneggenburger R, Meyer AC, Neher E (1999) Released fraction and total size of a pool of immediately available transmitter quanta and a calyx synapse. Neuron 23:399-409. 
Sharrow KM, Kumar A, Foster TC (2002) Calcineurin as a potential contributor in estradiol regulation of hippocampal synaptic function. Neuroscience 113:89-97.

Singh M, Setalo G, Guan X, Warren M, Toran-Allerand CD (1999) Estrogen-induced activation of mitogen-activated protein kinase in cerebral cortical explants: convergence of estrogen and neurotrophin signaling pathways. J Neurosci 19:1179-1188.

Smith MS, Freeman ME, Neill JD (1975) The control of progesterone secretion during the estrous cycle and early pseudopregnancy in the rat: prolactin, gonadotropin and steroid levels associated with rescue of the corpus luteum of pseudopregnancy. Endocrinology 96:219-226.

Stauffer SR, Coletta CJ, Tadesco R, Nishiguchi G, Carlson K, Sun J, Katzenellenbogen BS, Katzenellenbogen JA (2000) Pyrazole ligands: structureaffinity/activity relationships and estrogen receptor- $\alpha$-selective agonists. J Med Chem 43:4934-4947.

Stevens CF, Tsujimoto T (1995) Estimates for the pool size of releasable quanta at a singe central synapse and for the time required to refill the pool. Proc Natl Acad Sci U S A 92:846-849.

Stevens CF, Wang Y (1995) Facilitation and depression at single central synapses. Neuron 14:795-802.

Stevens CF, Wesseling JF (1998) Activity-dependent modulation of the rate at which synaptic vesicles become available to undergo exocytosis. Neuron 21:415-424.

Sun J, Huang YR, Harrington WR, Sheng S, Katzenellenbogen JA, Katzenellenbogen BS (2002) Antagonists selective for estrogen receptor $\alpha$. Endocrinology 143:941-947.

Teyler TJ, Vardaris RM, Lewis D, Rawitch AB (1980) Gonadal steroids: effects on excitability of hippocampal pyramidal cells. Science 209:1017-1019.

Tong G, Jahr CE (1994) Multivesicular release from excitatory synapses of cultured hippocampal neurons. Neuron 12:51-59.
Trussell LO, Zhang S, Raman IM (1993) Desensitization of AMPA receptors upon multiquantal neurotransmitter release. Neuron 10:1185-1196.

Turner DA, Chen Y, Isaac JT, West M, Wheal HV (1997) Excitatory synaptic site heterogeneity during paired pulse plasticity in CA1 pyramidal cells in rat hippocampus in vitro. J Physiol 500:441-461.

Wade CB, Dorsa DM (2003) Estrogen activation of cyclic adenosine 5' monophosphate response element-mediated transcription requires the extracellularly regulated kinase/mitogen-activated protein kinase pathway. Endocrinology 144:832-838.

Wesseling JF, Lo DC (2002) Limit on the role of activity in controlling the release-ready supply of synaptic vesicles. J Neurosci 22:9708-9720.

Wong M, Moss RL (1992) Long-term and short-term electrophysiological effects of estrogen on the synaptic properties of hippocampal CA1 neurons. J Neurosci 12:3217-3225.

Woolley CS, McEwen BS (1993) Roles of estradiol and progesterone in regulation of hippocampal dendritic spine density during the estrous cycle in the rat. J Comp Neurol 336:293-306.

Wu T-W, Wang JM, Chen S, Brinton RD (2005) $17 \beta$-estradiol induced $\mathrm{Ca}^{2+}$ influx via L-type calcium channels activates the src/erk/cyclic-AMP response element binding protein signal pathway and bcl-2 expression in rat hippocampal neurons: a potential initiation mechanism for estrogeninduced neuroprotection. Neuroscience 135:59-72.

Zhao L, Brinton RD (2007) Estrogen receptor $\alpha$ and $\beta$ differentially regulate intracellular $\mathrm{Ca}^{2+}$ dynamics leading to ERK phosphorylation and estrogen neuroprotection in hippocampal neurons. Brain Res 1172:48-59.

Zhao L, O’Neill K, Brinton RD (2006) Estrogenic agonist activity of ICI 182,780 (Faslodex) in hippocampal neurons: implications for basic science understanding of estrogen signaling and development of estrogen modulators with a dual therapeutic profile. J Pharmacol Exp Ther 319: $1124-1132$ 